CUBO A Mathematical Journal Vol.15, $N^{\underline{0}} 01$, (01-12). March 2013

\title{
Weak Solutions of Fractional Order Pettis Integral Inclusions with Multiple Time Delay in Banach Spaces
}

\author{
MOUFFAK BENCHOHRA \\ Université de Sidi Bel-Abbès \\ Laboratoire de Mathématiques, \\ BP 89, 22000 Sidi Bel-Abbès, Algérie \\ benchohra@univ-sba.dz
}

\author{
FAtima-Zohra Mostefai \\ Université de Saida \\ Département de Mathématiques, \\ BP 138 Cité Ennasr, 20000, Saida, Algérie \\ f.z.mostefai@gmail.com
}

\begin{abstract}
We study the existence of weak solutions for nonlinear integral inclusion with multiple time delay. The main result of the paper is based on the fixed point theorem of Mönch type and the technique of measure of weak noncompactness.
\end{abstract}

\section{RESUMEN}

Estudiamos la existencia de soluciones débiles de la inclusión integral no lineal con retardos temporales múltiples. El resultado principal del artículo se basa en el Teorema de Punto Fijo de tipo Mönch y la técnica de medida de la no-compacidad débil

Keywords and Phrases: Hyperbolic differential inclusion, measure of weak noncompactness, left sided mixed Pettis integral, weak solution, Banach space.

2010 AMS Mathematics Subject Classification: 26A33, 35H10, 35D30 


\section{Introduction}

Fractional differential equations have been of great interest recently. It is due to the development of the theory of fractional calculus itself and by application of such constructions in various fields of science and engineering such as control theory, physics, mechanics, electrochemistry, porous media, etc. There are many works discussing the solvability of nonlinear fractional differential equations and inclusions, see the monographs of Abbas et al. 2], Kilbas et al. [14, Lakshmikantham et al. [15], Podlubny [18, Tarasov [20], the papers of Agarwal et al. [3, 4, 5], Benchohra et al. [7, 8], Kilbas and Marzan [13], Salem [19], Vityuk and Golushkov [21], and the references therein.

In [12, R. W. Ibrahim and H. A. Jalab studied the existence of solutions of the following fractional integral inclusion

$$
u(t)-\sum_{i=1}^{m} b_{i}(t) u\left(t-\tau_{i}\right) \in I^{\alpha} F(t, u(t)) ; \text { if } t \in[0, T],
$$

where $\tau_{i}<t \in[0, T], b_{i}:[0, T] \rightarrow \mathbb{R}, i=1 \ldots, n$ are continuous functions, and $F:[0, T] \times \mathbb{R} \rightarrow \mathcal{P}(\mathbb{R})$ is a given multivalued map.

In [1], Abbas and Benchohra considered the following fractional integral equation with delay

$$
\begin{gathered}
u(x, y)=\sum_{i=1}^{m} g_{i}(x, y) u\left(x-\xi_{i}, y-\mu_{i}\right)+\operatorname{I}_{\theta}^{r} f(x, y, u(x, y)) ; \text { if }(x, y) \in J:=[0, a] \times[0, b] \\
u(x, y)=\Phi(x, y) ; \text { if }(x, y) \in \tilde{J}:=[-\xi, a] \times[-\mu, b] \backslash(0, a] \times(0, b]
\end{gathered}
$$

where $a, b>0, \theta=(0,0), \xi_{i}, \mu_{i} \geq 0 ; i=1 \ldots, m, \xi=\max _{i=1 \ldots, m}\left\{\xi_{i}\right\}, \mu=\max _{i=1 \ldots, m}\left\{\mu_{i}\right\}, I_{\theta}^{r}$ is the left-sided mixed Riemann-Liouville integral of order $r=\left(r_{1}, r_{2}\right) \in(0, \infty) \times(0, \infty), f$ : $J \times \mathbb{R}^{n} \rightarrow \mathbb{R}^{n}, g_{i}: J \rightarrow \mathbb{R} ; i=1 \ldots m$ are given continuous functions, and $\Phi: \tilde{J} \rightarrow \mathbb{R}^{n}$ is a given continuous function such that

$$
\Phi(x, 0)=\sum_{i=1}^{m} g_{i}(x, 0) \Phi\left(x-\xi_{i},-\mu_{i}\right) ; x \in[0, a],
$$

and

$$
\Phi(0, y)=\sum_{i=1}^{m} g_{i}(0, y) \Phi\left(-\xi_{i}, y-\mu_{i}\right) ; y \in[0, b]
$$

Motivated by the above papers, in this paper, we consider the following fractional integral inclusion with multiple time delay:

$$
\begin{gathered}
u(x, y)-\sum_{i=1}^{m} g_{i}(x, y) u\left(x-\xi_{i}, y-\mu_{i}\right) \in I_{\theta}^{\alpha} F(x, y, u(x, y)) ; \quad(x, y) \in J_{a} \times J_{b} \\
u(x, y)=\Psi(x, y) ; \quad(x, y) \in \tilde{J}=[-\xi, a] \times[-\mu, b] \backslash(0, a] \times(0, b]
\end{gathered}
$$


where $J_{a}=[0, a], \quad J_{b}=[0, b]$ for $a, b>0, \theta=(0,0), \xi=\max _{i=1 \ldots m}\left\{\xi_{i}\right\}, \mu=\max _{i=1 \ldots m}\left\{\mu_{i}\right\}, I_{\theta}^{\alpha}$ is the left sided mixed Pettis integral of order $\alpha, \alpha=\left(\alpha_{1}, \alpha_{2}\right) \in(0, \infty) \times(0, \infty), F: J_{a} \times J_{b} \times E \rightarrow$ $P(\mathrm{E})$ is a multivalued map $(P(\mathrm{E})$ is the family of all nonempty subsets of $\mathrm{E}), \mathrm{g}_{\mathrm{i}}: \mathrm{J}_{\mathrm{a}} \times \mathrm{J}_{\mathrm{b}} \rightarrow \mathbb{R} ; \mathrm{i}=$ $1, \ldots \mathrm{m}$ are given continuous functions, and $\Psi: \tilde{\mathrm{J}} \rightarrow \mathrm{E}$ is a given continuous function such that

$$
\Psi(0, y)=\sum_{i=1}^{m} g_{i}(0, y) \Psi\left(-\xi_{i}, y-\mu_{i}\right) ; y \in[0, b]
$$

and

$$
\Psi(x, 0)=\sum_{i=1}^{m} g_{i}(x, 0) \Psi\left(x-\xi_{i},-\mu_{i}\right) ; x \in[0, a] .
$$

$E$ is a Banach space with norm $\|$.$\| . Our result is based on fixed point theorem of Mönch type$ and the technique of measure of weak noncompactness. Let us mention that other tools like the nonlinear alternative of Leray-Schauder type, the Banach fixed point theorem and Schauder's fixed point theorem, such have been used to analyze the above problem in the scalar case [1, 2]. The present results complement and extend those considered in the scalar case.

\section{Preliminaries}

In this section, we introduce the notation, definitions, and preliminary facts that will be used in the remainder of this survey paper. Let $\mathbb{R}$ denote the real line and let $\mathrm{J}_{\mathrm{a}}=[0, \mathrm{a}]$ and $\mathrm{J}_{\mathrm{b}}=[0, \mathrm{~b}]$ be two closed and bounded intervals in $\mathbb{R}$ for some real numbers $a>0$ and $b>0$. Throughout the paper, $E$ is a Banach space with norm $\|$.$\| and dual E^{*}$. Also $(E, w)=\left(E, \sigma\left(E, E^{*}\right)\right)$ denotes the space $E$ with its weak topology. We take $C\left(J_{a} \times J_{b}, E\right)$ to be the Banach space of continuous functions $\mathrm{u}: \mathrm{J}_{\mathrm{a}} \times \mathrm{J}_{\mathrm{b}} \rightarrow \mathrm{E}$, with the usual supremum norm

$$
\|\mathfrak{u}\|_{\infty}=\sup \left\{\|\mathrm{u}(x, y)\|, \quad(x, y) \in J_{a} \times J_{b}\right\} .
$$

Definition 2.1. [17] The function $\mathrm{x}: \mathrm{J}_{\mathrm{a}} \times \mathrm{J}_{\mathrm{b}} \rightarrow \mathrm{E}$ is said to be Pettis integrable on $\mathrm{J}_{\mathrm{a}} \times \mathrm{J}_{\mathrm{b}}$ if and only if there is an element $\mathrm{x}_{\mathrm{I} \times \mathrm{J}} \in \mathrm{E}$ corresponding to each $\mathrm{I} \times \mathrm{J} \subset \mathrm{J}_{\mathrm{a}} \times \mathrm{J}_{\mathrm{b}}$ (I and $\mathrm{J}$ are measurable), such that $\varphi\left(\mathrm{x}_{\mathrm{I} \times \mathrm{J}}\right)=\int_{\mathrm{I}} \int_{\mathrm{J}} \varphi(\mathrm{x}(\mathrm{s}, \mathrm{t})) \mathrm{d}$ sdt for all $\varphi \in \mathrm{E}^{*}$ where the integral on the right is assumed to exist in the sense of Lebesgue (by definition, $\mathrm{x}_{\mathrm{I} \times \mathrm{J}}=\int_{\mathrm{I}} \int_{\mathrm{J}} \mathrm{x}(\mathrm{s}, \mathrm{t}) \mathrm{ds} \mathrm{dt}$ ).

We let $L^{1}\left(J_{a} \times J_{b}, E\right)$ denote the Banach space of measurable functions $u: J_{a} \times J_{b} \rightarrow E$ that are Pettis integrable, equipped with the norm

$$
\|\mathfrak{u}\|_{\mathrm{L}^{1}}=\int_{0}^{\mathrm{a}} \int_{0}^{\mathrm{b}}\|\mathfrak{u}(x, y)\| \mathrm{d} x \mathrm{~d} y .
$$

Let $P(E)$ is the family of all nonempty subsets of $\mathrm{E}$.

A multivalued map $\mathrm{G}: \mathrm{E} \rightarrow P(E)$ has convex (closed) valued if $\mathrm{G}(\mathrm{x})$ is convex (closed) for all $x \in E$. We say that $G$ is bounded on bounded sets if $G(B)$ is bounded in $E$ for each bounded set 
$B$ of $E$ (i.e. $\sup _{x \in B}\{\sup \{\|y\|: y \in G(x)\}\}<\infty$ ). The map $G$ is upper semicontinuous (u.s.c) on $E$ if for each $x_{0} \in E$, the set $G\left(x_{0}\right)$ is a nonempty closed subset of $E$ and for each open set $N$ of $E$ containing $G\left(x_{0}\right)$ there exists an open neighborhood $M$ of $x_{0}$ such that $G(M) \subseteq N$. The mapping $G$ has a fixed point if there exists $x \in E$ such that $x \in G(x)$.

In what follows $P_{c l}(E)=\{Y \in P(E): Y$ is closed $\}, P_{b}(E)=\{Y \in P(E): Y$ is bounded $\}$, $P_{c p}(E)=\{Y \in P(E): Y$ is compact $\}$, and $P_{c p, c v}(E)=\{Y \in P(E): Y$ is compact and convex $\}$.

A multivalued map $G: J_{a} \times J_{b} \rightarrow P_{c l}(E)$ is said to be measurable if for each $\omega \in E$ the function

$$
(x, y) \rightarrow \mathrm{d}(\omega, \mathrm{G}(x, y))=\inf \{|\omega-v|: v \in \mathrm{G}(x, y)\}
$$

is measurable. For more details on multivalued maps see the books of Aubin and Cellina [6], Deimling [10.

Definition 2.2. A function $\mathrm{h}: \mathrm{E} \rightarrow \mathrm{E}$ is said to be weakly sequentially continuous if $\mathrm{h}$ takes each weakly convergent sequence in $\mathrm{E}$ to weakly convergent sequence in $\mathrm{E}$ (ie for any $\left(\mathrm{x}_{\mathrm{n}}\right)_{\mathrm{n}}$ in $\mathrm{E}$ with $x_{n} \rightarrow x$ in $(\mathrm{E}, w), h\left(x_{n}\right) \rightarrow h((x))$ in $\left.(\mathrm{E}, w)\right)$.

Definition 2.3. A function $\mathrm{F}: \mathrm{Q} \rightarrow \mathrm{P}_{\mathrm{cl}, \mathrm{cv}}(\mathrm{Q})$ has weakly sequentially closed graph if for any sequence $\left(x_{n}, y_{n}\right) \in Q \times Q$, where $y_{n} \in F\left(x_{n}\right)$ for $n \in\{1,2, \ldots\}$, and where both $x_{n} \rightarrow x$ in $(E, \omega)$ and $\mathrm{y}_{\mathrm{n}} \rightarrow \mathrm{y}$ in $(\mathrm{E}, \omega)$ then $\mathrm{y} \in \mathrm{F}(\mathrm{x})$.

Proposition 2.4. [17, 11] If $\mathrm{x}($.$) is Pettis integrable and \mathrm{h}($.$) is a measurable and essentially$ bounded real-valued function, then $\mathrm{x}(.) \mathrm{h}($.$) is Pettis integrable.$

Definition 2.5. [9] Let $\mathrm{E}$ be a Banach space, $\Omega_{\mathrm{E}}$ the bounded subsets of $\mathrm{E}$ and $\mathrm{B}_{1}$ the unit ball of $\mathrm{E}$. The De Blasi measure of weak noncompactness is the map $\beta: \Omega_{\mathrm{E}} \rightarrow[0, \infty)$ defined by $\beta(X)=\inf \left\{\epsilon>0\right.$ : there exists a weakly compact subset $\Omega$ of $\left.E: X \subset \epsilon B_{1}+\Omega\right\}$

Properties: De Blasi measure of noncompactness satisfies some properties

(a) $\mathrm{A} \subset \mathrm{B} \Rightarrow \beta(\mathrm{A}) \leq \beta(\mathrm{B})$,

(b) $\beta(A)=0 \Leftrightarrow A$ is relatively compact,

(c) $\beta(A \cup B)=\max \{\beta(A), \beta(B)\}$,

(d) $\beta\left(\bar{A}^{\omega}\right)=\beta(A),\left(\bar{A}^{\omega}\right.$ denotes the weak closure of $A)$, (e) $\beta(A+B) \leq \beta(A)+\beta(B)$,

(f) $\beta(\lambda A)=|\lambda| \beta(A)$,

(g) $\beta(\operatorname{conv}(A))=\beta(A)$,

(h) $\beta\left(\cup_{|\lambda| \leq h} \lambda A=h \beta(A)\right.$.

The following result follows directly from the Hahn-Banach theorem.

Proposition 2.6. Let $\mathrm{E}$ be a normed space with $\mathrm{x}_{0} \neq 0$ then there exists $\varphi \in \mathrm{E}^{*}$ with $\|\varphi\|=1$ and $\varphi\left(x_{0}\right)=\left\|x_{0}\right\|$. 
For a given set $\mathrm{V}$ of functions $v: \mathrm{J}_{\mathrm{a}} \times \mathrm{J}_{\mathrm{b}} \rightarrow \mathrm{E}$ let us denote by

$$
\mathrm{V}(x, y)=\{v(x, y), v \in V\},(x, y) \in J_{a} \times J_{b}
$$

and

$$
\mathrm{V}\left(\mathrm{J}_{\mathrm{a}} \times \mathrm{J}_{\mathrm{b}}\right)=\left\{v(x, y): v \in \mathrm{V},(x, y) \in \mathrm{J}_{\mathrm{a}} \times \mathrm{J}_{\mathrm{b}}\right\}
$$

For completeness, we recall the definition of the fractional Pettis-integral of order $\alpha>0$. Let $\alpha_{1}, \alpha_{2}>0$ and $\alpha=\left(\alpha_{1}, \alpha_{2}\right)$. For $h \in \mathrm{L}^{1}\left(\mathrm{~J}_{\mathrm{a}} \times \mathrm{J}_{\mathrm{b}}, \mathrm{E}\right)$, the expression

$$
\left(I_{0}^{\alpha} h\right)(x, y)=\frac{1}{\Gamma\left(\alpha_{1}\right) \Gamma\left(\alpha_{2}\right)} \int_{0}^{x} \int_{0}^{y}(x-s)^{\alpha_{1}-1}(y-t)^{\alpha_{2}-1} h(s, t) d s d t
$$

where the sign " $\int "$ denotes the Pettis integral and $\Gamma($.$) is the Euler gamma function, is called the$ left sided mixed Pettis integral of order $\alpha$.

For our purpose we will need the following fixed point theorem.

Theorem 2.7. [16] Let $\mathrm{E}$ be a Banach space with $\mathrm{Q}$ a nonempty, bounded, closed, convex and equicontinuous subset of metrizable locally convex vector space $\mathrm{C}(\mathrm{J}, \mathrm{E})$ such that $\mathrm{O} \in \mathrm{Q}$. Suppose that $\mathrm{T}: \mathrm{Q} \rightarrow \mathrm{P}_{\mathrm{cl}, \mathrm{cv}}(\mathrm{Q})$ has weakly-sequentially closed graph. If the implication

$$
\overline{\mathrm{V}}=\overline{\operatorname{conv}}(\{0\} \cup \mathrm{T}(\mathrm{V})) \Rightarrow \mathrm{V} \text { is relatively weakly compact, }
$$

holds for every subset $\mathrm{V} \subset \mathrm{Q}$, then the operator $\mathrm{T}$ has a fixed point.

\section{Main Results}

we first define what we mean by solution of the problem (4)-(5).

Definition 3.1. A function $\mathrm{u} \in \mathrm{C}(\mathrm{J}, \mathrm{E})$ is said to be solution of problem (4)-(5) if there exists a function $v \in \mathrm{L}^{1}\left(\mathrm{~J}_{\mathrm{a}} \times \mathrm{J}_{\mathrm{b}}, \mathrm{E}\right)$ with $v(\mathrm{x}, \mathrm{y}) \in \mathrm{F}(\mathrm{x}, \mathrm{y}, \mathrm{u}(\mathrm{x}, \mathrm{y}))$ and such that

$$
u(x, y)=\sum_{i=1}^{m} g_{i}(x, y) u\left(x-\xi_{i}, y-\mu_{i}\right)+\frac{1}{\Gamma\left(\alpha_{1}\right) \Gamma\left(\alpha_{2}\right)} \int_{0}^{x} \int_{0}^{y}(x-s)^{\alpha_{1}-1}(y-t)^{\alpha_{2}-1} v(s, t) d s d t
$$

and the function $\mathrm{u}$ satisfies condition (5) on $\tilde{\mathrm{J}}$.

For any $u \in C\left(J_{a} \times J_{b}, E\right)$, we define the set

$$
S_{F, u}=\left\{v \in L^{1}\left(J_{a} \times J_{b}, E\right), v(x, y) \in F(x, y, u(x, y)),(x, y) \in J_{a} \times J_{b}\right\}
$$

This is known as the set of selection function. Set

$$
\mathrm{G}=\max _{i=1 \ldots m}\left\{\sup _{(x, y) \in \mathrm{J}_{\mathrm{a}} \times \mathrm{J}_{\mathrm{b}}}\left|g_{i}(x, y)\right|\right\}
$$

We are now in the position to state and prove our existence result for the problem (44)-(5). We first list the following hypotheses. 
$(\mathrm{H} 1) \mathrm{F}: \mathrm{J}_{\mathrm{a}} \times \mathrm{J}_{\mathrm{b}} \times \mathrm{E} \rightarrow \mathrm{P}_{\mathrm{cp}, \mathrm{cl}, \mathrm{cv}}(\mathrm{E})$, has weakly sequentially closed graph.

(H2) For each $u \in C\left(J_{a} \times J_{b}, E\right)$, there exists a measurable function $v: J_{a} \times J_{b} \rightarrow E$ with $v(x, y) \in$ $\mathrm{F}(x, y, u(x, y))$ a.e. on $\mathrm{J}_{\mathrm{a}} \times \mathrm{J}_{\mathrm{b}}$ and $v$ is Pettis integrable on $\mathrm{J}_{\mathrm{a}} \times \mathrm{J}_{\mathrm{b}}$.

(H3) There exists $p \in \mathrm{L}^{\infty}\left(\mathrm{J}_{\mathrm{a}} \times \mathrm{J}_{\mathrm{b}}, \mathbb{R}_{+}\right)$such that

$$
\|\mathrm{F}(\mathrm{x}, \mathrm{y}, \mathrm{u})\|_{\mathrm{p}}=\sup \{\|v\|: v \in \mathrm{F}(\mathrm{x}, \mathrm{y}, \mathrm{u})\} \leq \mathrm{p}(\mathrm{x}, \mathrm{y}),
$$

for $(x, y) \in J_{a} \times J_{b}$ and each $u \in E$.

(H4) There exists a number $\mathrm{R}>0$ such that

$$
\frac{p^{*} a^{\alpha_{1}} b^{\alpha_{2}}}{\Gamma\left(\alpha_{1}+1\right) \Gamma\left(\alpha_{2}+1\right)(1-m G)}<R
$$

where $p^{*}=\|p\|_{\infty}$.

(H5) Let $r_{0}>0$ be arbitrary (but fixed). For any $\epsilon>0$ and for any subset $X \subset B_{r_{0}}$, there exists a closed subset $I_{\epsilon} \subset J_{a} \times J_{b}$ such that $\mu\left(J_{a} \times J_{b} \backslash I_{\epsilon}\right)<\epsilon$ and

$$
\beta(F(T \times X)) \leq \sup _{(x, y) \in T} p(x, y) \beta(X),
$$

for each closed subset $T$ of $I_{\epsilon}$, where $\mu$ denotes the Lebesgue measure in $\mathbb{R}^{2}$.

The main result in this paper reads as follows.

Theorem 3.2. Assume that assumptions (H1)-(H5) hold. If

$$
\mathrm{mG}+\frac{\mathrm{p}^{*} \mathrm{a}^{\alpha_{1}} \mathrm{~b}^{\alpha_{2}}}{\Gamma\left(\alpha_{1}+1\right) \Gamma\left(\alpha_{2}+1\right)}<1
$$

then problem (4)-(5) has at least one solution on $\mathrm{J}$.

Proof. To transform problem (4)-(5) into a fixed point problem, we define a multivalued map $\Omega: C(J, E) \rightarrow P_{c l}(C(J, E))$ as

$$
\Omega(u)=\{h \in C(J, E) \text { such that }
$$

$$
h(x, y)= \begin{cases}\Psi(x, y) & \text { if }(x, y) \in \tilde{J}, \\ \sum_{i=1}^{m} g_{i}(x, y) u\left(x-\xi_{i}, y-\mu_{i}\right) & \text { if } v \in S_{F, u}, \\ +\frac{1}{\Gamma\left(\alpha_{1}\right) \Gamma\left(\alpha_{2}\right)} \int_{0}^{x} \int_{0}^{y}(x-s)^{\alpha_{1}-1}(y-t)^{\alpha_{2}-1} v(s, t) d s d t ; & (x, y) \in J_{a} \times J_{b}\end{cases}
$$

where $\Psi(\cdot, \cdot)$ is the function defined by (5). Now, we prove that $\Omega$ satisfies all the assumptions of the Theorem 2.7 and thus $\Omega$ has a fixed point which is a solution of problem (44)-(5). 
First notice that, for all $u \in C(J, E)$, there exists a Pettis integral $v: J_{a} \times J_{b} \rightarrow E$ such that $v(x, y) \in F(x, y, u(x, y))$ for a.e. $(x, y) \in J_{a} \times J_{b}$ (Assumption $\left.(H 2)\right)$ then $\varphi(v(x, y)) \in L^{1}\left(J_{a} \times J_{b}\right)$ for any $\varphi \in E^{*}$. From the definition of the integral of fractional order we have

$$
\begin{aligned}
I^{\alpha} \varphi(v(x, y,)) & =\int_{0}^{x} \int_{0}^{y} \frac{(x-s)^{\alpha_{1}-1}(y-t)^{\alpha_{2}-1}}{\Gamma\left(\alpha_{1}\right) \Gamma\left(\alpha_{2}\right)} \varphi(v(s, t)) d s d t \\
& =\int_{0}^{x} \int_{0}^{y} \varphi\left(\frac{(x-s)^{\alpha_{1}-1}(y-t)^{\alpha_{2}-1}}{\Gamma\left(\alpha_{1}\right) \Gamma\left(\alpha_{2}\right)} v(s, t)\right) d s d t
\end{aligned}
$$

exists for almost every $(x, y) \in J_{a} \times J_{b}$ and is an element from $L^{1}\left(J_{a} \times J_{b}\right)$, that is, for almost every $(x, y) \in J_{a} \times J_{b}, s \in(0, x), t \in(0, y)$ the measurable function

$$
\varphi\left(\frac{(x-s)^{\alpha_{1}-1}(y-t)^{\alpha_{2}-1}}{\Gamma\left(\alpha_{1}\right) \Gamma\left(\alpha_{2}\right)} v(s, t)\right)=\frac{(x-s)^{\alpha_{1}-1}(y-t)^{\alpha_{2}-1}}{\Gamma\left(\alpha_{1}\right) \Gamma\left(\alpha_{2}\right)} \varphi(v(s, t))
$$

is Lebesgue integrable, hence the function $(s, t) \rightarrow \frac{(x-s)^{\alpha_{1}-1}(y-t)^{\alpha_{2}-1}}{\Gamma\left(\alpha_{1}\right) \Gamma\left(\alpha_{2}\right)} v(s, t)$ is Pettis integrable on $\mathrm{J}_{\mathrm{a}} \times \mathrm{J}_{\mathrm{b}}$, and thus the operator $\Omega$ is well defined.

Let $\mathrm{R}>0$ and consider the set

$$
\begin{aligned}
Q= & \left\{u \in C(J, E):\|u\|_{\infty} \leq R\right. \\
& \text { and }\left\|u\left(x_{2}, y_{2}\right)-u\left(x_{1}, y_{1}\right)\right\| \leq R \sum_{i=1}^{m}\left|g_{i}\left(x_{2}, y_{2}\right)-g_{i}\left(x_{1}, y_{1}\right)\right| \\
& \left.+\frac{p^{*}}{\Gamma\left(\alpha_{1}+1\right) \Gamma\left(\alpha_{2}+1\right)}\left[x_{2}^{\alpha_{1}} y_{2}^{\alpha_{2}}-x_{1}^{\alpha_{1}} y_{1}^{\alpha_{2}}\right] ; \text { for }\left(x_{1}, y_{1}\right),\left(x_{2}, y_{2}\right) \in J_{a} \times J_{b}\right\}
\end{aligned}
$$

Clearly, the subset $\mathrm{Q}$ is closed, bounded, convex and equicontinuous subset of a metrisable locally convex vector space $C(J, E)$. The remainder of the proof will be given in four steps.

Step 1: $\Omega(u)$ is convex for each $u \in Q$.

For that, let $0<\lambda<1, h_{1}, h_{2} \in \Omega(u)$, obviously if $(x, y) \in \tilde{J}$ then $\lambda h_{1}(x, y)+(1-\lambda) h_{2}(x, y) \in$ $\Omega(u)$. Now if $(x, y) \in J_{a} \times J_{b}$, then there exists $v_{1}, v_{2} \in S_{F, u}$ such that

$$
h_{i}(x, y)=\sum_{i=1}^{m} g_{i}(x, y) u\left(x-\xi_{i}, y-\mu_{i}\right)+\frac{1}{\Gamma\left(\alpha_{1}\right) \Gamma\left(\alpha_{2}\right)} \int_{0}^{x} \int_{0}^{y}(x-s)^{\alpha_{1}-1}(y-t)^{\alpha 2-1} v_{i}(s, t) d s d t
$$

$i=1,2$, Then for each $(x, y) \in J_{a} \times J_{b}$ we have

$$
\begin{aligned}
& \left(\lambda h_{1}+(1-\lambda) h_{2}\right)(x, y)=\sum_{i=1}^{m} g_{i}(x, y) u\left(x-\xi_{i}, y-\mu_{i}\right) \\
+ & \frac{1}{\Gamma\left(\alpha_{1}\right) \Gamma\left(\alpha_{2}\right)} \int_{0}^{x} \int_{0}^{y}(x-s)^{\alpha_{1}-1}(y-t)^{\alpha_{2}-1}\left(\lambda v_{1}(s, t)+(1-\lambda) v_{2}(s, t)\right) d s d t .
\end{aligned}
$$


Since $S_{F, u}$ is convex ( because $F$ has convex values), it follows that $\lambda h_{1}+(1-\lambda) h_{2} \in \Omega(u)$.

Step 2: $\Omega$ maps $Q$ into $Q$.

To see this, take $h \in \Omega Q$. Then there exists $u \in Q$ with $h \in \Omega u$. And there exists $v$ : $\mathrm{J}_{\mathrm{a}} \times \mathrm{J}_{\mathrm{b}} \rightarrow \mathrm{E}$ Pettis integrable with $v(x, y) \in \mathrm{F}(x, y, u(x, y))$

$$
h(x, y)= \begin{cases}\Psi(x, y) & \text { if }(x, y) \in \tilde{J} \\ \sum_{i=1}^{m} g_{i}(x, y) u\left(x-\xi_{i}, y-\mu_{i}\right) & \text { if } v \in S_{F, u} \\ +\frac{1}{\Gamma\left(\alpha_{1}\right) \Gamma\left(\alpha_{2}\right)} \int_{0}^{x} \int_{0}^{y}(x-s)^{\alpha_{1}-1}(y-t)^{\alpha_{2}-1} v(s, t) d s d t ; & (x, y) \in J_{a} \times J_{b}\end{cases}
$$

We can consider that $h(x, y) \neq 0$ and by Proposition 2.6 there exists $\varphi \in E^{*}$ with $\|\varphi\|=1$ and $\varphi(h(x, y))=\|h(x, y)\|$ for $(x, y) \in J_{a} \times J_{b}$, we have

$$
\begin{aligned}
\|h(x, y)\| & =\varphi(h(x, y)) \\
& =\varphi\left(\sum_{i=1}^{m} g_{i}(x, y) u\left(x-\xi_{i}, y-\mu_{i}\right)\right. \\
& \left.+\frac{1}{\Gamma\left(\alpha_{1}\right) \Gamma\left(\alpha_{2}\right)} \int_{0}^{x} \int_{0}^{y}(x-s)^{\alpha_{1}-1}(y-t)^{\alpha_{2}-1} v(s, t) d s d t\right) \\
& =\varphi\left(\sum_{i=1}^{m} g_{i}(x, y) u\left(x-\xi_{i}, y-\mu_{i}\right)\right) \\
& +\varphi\left(\frac{1}{\Gamma\left(\alpha_{1}\right) \Gamma\left(\alpha_{2}\right)} \int_{0}^{x} \int_{0}^{y}(x-s)^{\alpha_{1}-1}(y-t)^{\alpha_{2}-1} v(s, t) d s d t\right) \\
& \leq m G R+\frac{p^{*}}{\Gamma\left(\alpha_{1}\right) \Gamma\left(\alpha_{2}\right)} \int_{0}^{x} \int_{0}^{y}(x-s)^{\alpha_{1}-1}(y-t)^{\alpha_{2}-1} d s d t \\
& \leq m G R+\frac{p^{*} a^{\alpha_{1}} b^{\alpha_{2}}}{\Gamma\left(\alpha_{1}+1\right) \Gamma\left(\alpha_{2}+1\right)} \leq R .
\end{aligned}
$$

on the other hand, for $(x, y) \in \tilde{J}$, we have

$$
\|h(x, y)\|=\varphi(h(x, y)) \leq R
$$

Next, suppose that $\left(x_{1}, y_{1}\right),\left(x_{2}, y_{2}\right) \in J_{a} \times J_{b}$ with $x_{1}<x_{2}$ and $y_{1}<y_{2}$, and let $h \in \Omega u$, so $h\left(x_{1}, y_{1}\right)-h\left(x_{2}, y_{2}\right) \neq 0$. Then there exists $\varphi \in E^{*}$ such that

$$
\left\|h\left(x_{1}, y_{1}\right)-h\left(x_{2}, y_{2}\right)\right\|=\varphi\left(h\left(x_{1}, y_{1}\right)-h\left(x_{2}, y_{2}\right)\right)
$$

and $\|\varphi\|=1$. Thus 


$$
\begin{aligned}
& \left\|h\left(x_{2}, y_{2}\right)-h\left(x_{1}, y_{1}\right)\right\| \\
& =\varphi\left(\sum_{i=1}^{m} g_{i}\left(x_{2}, y_{2}\right) u\left(x_{2}-\xi_{i}, y_{2}-\mu_{i}\right)\right. \\
& +\frac{1}{\Gamma\left(\alpha_{1}\right) \Gamma\left(\alpha_{2}\right)} \int_{0}^{x_{2}} \int_{0}^{y_{2}}\left(x_{2}-s\right)^{\alpha_{1}-1}\left(y_{2}-t\right)^{\alpha_{2}-1} v(s, t) d s d t \\
& -\sum_{i=1}^{m} g_{i}\left(x_{1}, y_{1}\right) u\left(x_{1}-\xi_{i}, y_{1}-\mu_{i}\right) \\
& \left.+\frac{1}{\Gamma\left(\alpha_{1}\right) \Gamma\left(\alpha_{2}\right)} \int_{0}^{x_{1}} \int_{0}^{y_{1}}\left(x_{1}-s\right)^{\alpha_{1}-1}\left(y_{1}-t\right)^{\alpha_{2}-1} v(s, t) d s d t\right) \\
& =\varphi\left(\sum_{i=1}^{m} g_{i}\left(x_{2}, y_{2}\right) u\left(x_{2}-\xi_{i}, y_{2}-\mu_{i}\right)-\sum_{i=1}^{m} g_{i}\left(x_{1}, y_{1}\right) u\left(x_{1}-\xi_{i}, y_{1}-\mu_{i}\right)\right) \\
& +\varphi\left(\frac{1}{\Gamma\left(\alpha_{1}\right) \Gamma\left(\alpha_{2}\right)} \int_{x_{1}}^{x_{2}} \int_{y_{1}}^{y_{2}}\left(x_{2}-s\right)^{\alpha_{1}-1}\left(y_{2}-t\right)^{\alpha_{2}-1} v(s, t) d s d t\right. \\
& +\frac{1}{\Gamma\left(\alpha_{1}\right) \Gamma\left(\alpha_{2}\right)} \int_{0}^{x_{1}} \int_{0}^{y_{1}}\left[\left(x_{2}-s\right)^{\alpha_{1}-1}\left(y_{2}-t\right)^{\alpha_{2}-1}-\left(x_{1}-s\right)^{\alpha_{1}-1}\left(y_{1}-t\right)^{\alpha_{2}-1}\right] \\
& \times v(s, t) d s d t+\frac{1}{\Gamma\left(\alpha_{1}\right) \Gamma\left(\alpha_{2}\right)} \int_{0}^{x_{1}} \int_{y_{1}}^{y_{2}}\left(x_{2}-s\right)^{\alpha_{1}-1}\left(y_{2}-t\right)^{\alpha_{2}-1} v(s, t) d s d t \\
& \left.+\frac{1}{\Gamma\left(\alpha_{1}\right) \Gamma\left(\alpha_{2}\right)} \int_{x_{1}}^{x_{2}} \int_{0}^{y_{1}}\left(x_{2}-s\right)^{\alpha_{1}-1}\left(y_{2}-t\right)^{\alpha_{2}-1} v(s, t) d s d t\right) \\
& \leq \sum_{i=1}^{m}\left\|g_{i}\left(x_{2}, y_{2}\right) u\left(x_{2}-\xi_{i}, y_{2}-\mu_{i}\right)-g_{i}\left(x_{1}, y_{1}\right) u\left(x_{1}-\xi_{i}, y_{1}-\mu_{i}\right)\right\| \\
& +\frac{p^{*}}{\Gamma\left(\alpha_{1}\right) \Gamma\left(\alpha_{2}\right)} \int_{0}^{x_{1}} \int_{0}^{y_{1}}\left[\left(x_{2}-s\right)^{\alpha_{1}-1}\left(y_{2}-t\right)^{\alpha_{2}-1}-\left(x_{1}-s\right)^{\alpha_{1}-1}\left(y_{1}-t\right)^{\alpha_{2}-1}\right] d s d t \\
& +\frac{p^{*}}{\Gamma\left(\alpha_{1}\right) \Gamma\left(\alpha_{2}\right)} \int_{x_{1}}^{x_{2}} \int_{y_{1}}^{y_{2}}\left(x_{2}-s\right)^{\alpha_{1}-1}\left(y_{2}-t\right)^{\alpha_{2}-1} d s d t \\
& +\frac{p^{*}}{\Gamma\left(\alpha_{1}\right) \Gamma\left(\alpha_{2}\right)} \int_{0}^{x_{1}} \int_{y_{1}}^{y_{2}}\left(x_{2}-s\right)^{\alpha_{1}-1}\left(y_{2}-t\right)^{\alpha_{2}-1} d s d t \\
& +\frac{p^{*}}{\Gamma\left(\alpha_{1}\right) \Gamma\left(\alpha_{2}\right)} \int_{x_{1}}^{x_{2}} \int_{0}^{y_{1}}\left(x_{2}-s\right)^{\alpha_{1}-1}\left(y_{2}-t\right)^{\alpha_{2}-1} d s d t \\
& \leq R \sum_{i=1}^{m}\left\|g_{i}\left(x_{2}, y_{2}\right)-g_{i}\left(x_{1}, y_{1}\right)\right\|+\frac{p^{*}}{\Gamma\left(\alpha_{1}+1\right) \Gamma\left(\alpha_{2}+1\right)}\left[x_{2}^{\alpha_{1}} y_{2}^{\alpha_{2}}-x_{1}^{\alpha_{1}} y_{1}^{\alpha_{2}}\right] \text {. }
\end{aligned}
$$

This implies that $\mathrm{h} \in \mathrm{Q}$, hence $\Omega \mathrm{Q} \subset \mathrm{Q}$

Step 3: $\Omega$ has weakly sequentially closed graph.

Let $\left(u_{n}, w_{n}\right)$ be a sequence in $Q \times Q$ with $u_{n}(x, y) \rightarrow u(x, y)$ in $(E, w)$ for each $(x, y) \in J_{a} \times J_{b}$, $w_{n}(x, y) \rightarrow w(x, y)$ in $(E, w)$ for each $(x, y) \in J_{a} \times J_{b}$ and $w_{n} \in \Omega\left(u_{n}\right)$ for $n \in\{1,2, \ldots\}$. We show that $w \in \Omega(u)$.

Since $w_{n} \in \Omega\left(u_{n}\right)$, there exists $v_{n} \in S_{F, u_{n}}$ such that $w_{n}(x, y)=\sum_{i=1}^{m} g_{i}(x, y) u_{n}\left(x-\xi_{i}, y-\mu_{i}\right)+\frac{1}{\Gamma\left(\alpha_{1}\right) \Gamma\left(\alpha_{2}\right)} \int_{0}^{x} \int_{0}^{y}(x-s)^{\alpha_{1}-1}(y-t)^{\alpha 2-1} v_{n}(s, t) d s d t$ 
We show that there exists $v \in S_{\mathrm{F}, \mathrm{u}}$ such that

$$
w(x, y)=\sum_{i=1}^{m} g_{i}(x, y) u\left(x-\xi_{i}, y-\mu_{i}\right)+\frac{1}{\Gamma\left(\alpha_{1}\right) \Gamma\left(\alpha_{2}\right)} \int_{0}^{x} \int_{0}^{y}(x-s)^{\alpha_{1}-1}(y-t)^{\alpha 2-1} v(s, t) d s d t .
$$

Since $F(\cdot, \cdot, \cdot)$ has compact values, there exists a subsequence $v_{n_{m}} \in S_{F, u_{n}}$ such that $v_{n_{m}}$ is Pettis integrable and

$$
v_{n_{m}}(x, y) \in F\left(x, y, u_{n}(x, y)\right) \text { a.e. }(x, y) \in J_{a} \times J_{b}
$$

and

$$
v_{n_{m}}(\cdot, \cdot) \rightarrow v(\cdot, \cdot) \text { in }(E, w) \text { as } m \rightarrow \infty
$$

As $F(x, y, \cdot)$ has weakly sequentially closed graph, $v(x, y) \in F(x, y, u(x, y))$. Then Lebesgue Dominated Convergence theorem for Pettis integral implies that

$\varphi\left(w_{n}(x, y)\right) \rightarrow \varphi\left(\sum_{i=1}^{m} g_{i}(x, y) u\left(x-\xi_{i}, y-\mu_{i}\right)+\frac{1}{\Gamma\left(\alpha_{1}\right) \Gamma\left(\alpha_{2}\right)} \int_{0}^{x} \int_{0}^{y}(x-s)^{\alpha_{1}-1}(y-t)^{\alpha_{2}-1} v(s, t) d s d t\right)$

i.e. $w_{n}(x, y) \rightarrow \Omega u(x, y)$ in $(E, w)$. Since this holds, for each $(x, y) \in J_{a} \times J_{b}$, we have $w \in \Omega u$.

Step 4: the implication (6) holds.

Let $V$ be a subset of $Q$ such that $\bar{V}=\overline{\operatorname{conv}}(\Omega(V) \cup\{0\})$. Obviously $V(x, y) \subset \overline{\operatorname{conv}}(\Omega(V(x, y)) \cup$ $\{0\}), \forall(x, y) \in J$. Further, as $V$ is bounded and equicontinuous, the function $(x, y) \rightarrow v(x, y)=$ $\beta(V(x, y))$ is continuous on $\mathrm{J}$.

If $(x, y) \in \tilde{J}$ then

$$
\Omega V(x, y)=\{\Omega u(x, y): u \in V\}=\{\Psi(x, y):(x, y) \in \tilde{J}\}
$$

and since $\Psi$ is continuous on $[-\xi, 0] \times[-\mu, 0]$, the set $\overline{\{\Psi(x, y),(x, y) \in[-\xi, 0] \times[-\mu, 0]\}} \subset E$ is compact. Now by $(\mathrm{H} 3)$ and the properties of the measure $\beta$, for any $(x, y) \in J_{a} \times J_{b}$, we have

$$
\begin{aligned}
v(x, y) & \leq \beta((\Omega V)(x, y) \cup\{0\}) \\
& \leq \beta((\Omega V)(x, y)) \\
& \leq \beta\{\Omega u(x, y): u \in V\} \\
& \leq \beta\left\{\sum_{i=1}^{m} g_{i}(x, y) u\left(x-\xi_{i}, y-\mu_{i}\right) ; u \in V\right\} \\
& +\beta\left\{\frac{1}{\Gamma\left(\alpha_{1}\right) \Gamma\left(\alpha_{2}\right)} \int_{0}^{x} \int_{0}^{y}(x-s)^{\alpha_{1}-1}(y-t)^{\alpha_{2}-1} v(s, t) d s d t ; v(x, y) \in F(x, y, u), u \in V\right\} \\
& \leq \sum_{i=1}^{m} \beta\left(\left\{g_{i}(x, y) u\left(x-\xi_{i}, y-\mu_{i}\right) ; u \in V\right\}\right)
\end{aligned}
$$




$$
\begin{aligned}
& +\frac{1}{\Gamma\left(\alpha_{1}\right) \Gamma\left(\alpha_{2}\right)} \beta\left\{\int_{0}^{x} \int_{0}^{y}(x-s)^{\alpha_{1}-1}(y-t)^{\alpha_{2}-1} v(s, t) d s d t ; v(x, y) \in F(x, y, u), u \in V\right\} \\
& \leq \sum_{i=1}^{m}\left|g_{i}(x, y)\right| \beta(V(x, y)) \\
& +\frac{1}{\Gamma\left(\alpha_{1}\right) \Gamma\left(\alpha_{2}\right)} \int_{0}^{x} \int_{0}^{y}(x-s)^{\alpha_{1}-1}(y-t)^{\alpha_{2}-1} p(s, t) \beta(V(s, t)) d s d t \\
& \leq m G\|v\|_{\infty}+\frac{p^{*} a^{\alpha_{1}} b^{\alpha_{2}}}{\Gamma\left(\alpha_{1}+1\right) \Gamma\left(\alpha_{2}+1\right)}\|v\|_{\infty}
\end{aligned}
$$

In particular,

$$
\|v\|_{\infty} \leq\|v\|_{\infty}\left(m G+\frac{p^{*} a^{\alpha_{1}} b^{\alpha_{2}}}{\Gamma\left(\alpha_{1}+1\right) \Gamma\left(\alpha_{2}+1\right)}\right) .
$$

By (8) it follows that $\|v\|_{\infty}=0$, that is $v(x, y)=\beta(V(x, y))=0$ for each $(x, y) \in J$ and then $V$ is weakly relatively compact in $C(J, E)$. Applying now Theorem 2.7 we conclude that $T$ has a fixed point which is a solution of problem (4)-(15).

Received: October 2012. Revised: February 2013.

\section{References}

[1] S. Abbas and M. Benchohra, Fractional order Riemann-Liouville integral equations with multiple time delay, Appl. Math. E-Notes 12 (2012), 79-87.

[2] S. Abbas, M. Benchohra and G.M. N'Guérékata, Topics in Fractional Differential Equations, Springer, New York, 2012.

[3] R.P. Agarwal, M. Belmekki, and M. Benchohra, A survey on semilinear differential equations and inclusions involving Riemann-Liouville fractional derivative. Adv. Difference Equ. 2009, Art. ID 981-728, 47 pp.

[4] R.P Agarwal, M. Benchohra and S. Hamani, A survey on existence result for boundary value problems of nonlinear fractional differential equations and inclusions, Acta. Appl. Math. 109 (3) (2010), 973-1033.

[5] R. P. Agarwal, M. Benchohra, D. Seba, On the application of measure of noncompactness to the existence of solutions for fractional differential equations, Results Math. 55 (2009), 221-230.

[6] J.P. Aubin and A. Cellina, Differential Inclusions, Springer-Verlag, Berlin-Heidelberg, New York, (1984)

[7] M. Benchohra, A. Cabada, and D. Seba, An existence result for nonlinear fractional differential equations on Banach spaces, Bound. Value Probl. 2009, Art. ID 628916, 11 pp. 
[8] M. Benchohra, J. Henderson, and D. Seba, Measure of noncompactness and fractional differential equations in Banach spaces, Commun. Appl. Anal. 12 (2008), 419-428.

[9] F. S. De Blasi, On the property of the unit sphere in a Banach space, Bull. Math. Soc. Sci. Math. Roumanie (N.S.) 21 (1977), 259-262.

[10] K. Deimling, Multivalued Differential Equations, De Gruyter, Berlin-New York, 1992.

[11] J. Diestel, J. J. Uhl Jr., Vector Measures, in: Math. Surveys, vol. 15, Amer. Math. Soc., Providence, R.I., 1977.

[12] R. W. Ibrahim and H. A. Jalab, Existence of the solution of fractional integral inclusion with time delay, Misk. Math. Notes 11 (2) (2010), 139-150.

[13] A. A. Kilbas and S. A. Marzan, Nonlinear differential equations with the Caputo fractional derivative in the space of continuously differentiable functions, Differential Equations 41 (2005), 84-89.

[14] A. A. Kilbas, Hari M. Srivastava, and Juan J. Trujillo, Theory and Applications of Fractional Differential Equations. North-Holland Mathematics Studies, 204. Elsevier Science B.V., Amsterdam, 2006.

[15] V. Lakshmikantham, S. Leela and J. Vasundhara, Theory of Fractional Dynamic Systems, Cambridge Academic Publishers, Cambridge, 2009.

[16] D. O'Regan, Fixed point theory for weakly sequentially continuous mapping, Math. Comput. Model. 27 (5) (1998), 1-14.

[17] B.J. Pettis, On integration in vector spaces, Trans. Amer. Math. Soc. 44 (1938), 277-304.

[18] I. Podlubny, Fractional Differential Equation, Academic Press, San Diego, 1999.

[19] H.A.H. Salem, On the fractional order m-point boundary value problem in reflexive Banach spaces and weak topologies, Comput. Math. Appl. 224 (2009), 565-572.

[20] V. E. Tarasov, Fractional Dynamics: Application of Fractional Calculus to Dynamics of Particles, Fields and Media, Springer, Heidelberg; Higher Education Press, Beijing, 2010.

[21] A. N. Vityuk and A. V. Golushkov, Existence of solutions of systems of partial differential equations of fractional order, Nonlinear Oscil. 7 (3) (2004), 318-325. 